LAWRENCE LIVERMORE N A T IO N A L LABORATORY

\section{Dynamic Data-Driven Event Reconstruction for Atmospheric Releases}

G. Sugiyama, B. Kosovic, W. Hanley, G. Johannesson, S. Larsen, G. Loosmore, J. Lundquist, A. Mirin, J. Nitao, R. Serban, K. Dyer

October 29, 2004 
This document was prepared as an account of work sponsored by an agency of the United States Government. Neither the United States Government nor the University of California nor any of their employees, makes any warranty, express or implied, or assumes any legal liability or responsibility for the accuracy, completeness, or usefulness of any information, apparatus, product, or process disclosed, or represents that its use would not infringe privately owned rights. Reference herein to any specific commercial product, process, or service by trade name, trademark, manufacturer, or otherwise, does not necessarily constitute or imply its endorsement, recommendation, or favoring by the United States Government or the University of California. The views and opinions of authors expressed herein do not necessarily state or reflect those of the United States Government or the University of California, and shall not be used for advertising or product endorsement purposes.

This work was performed under the auspices of the U.S. Department of Energy by University of California, Lawrence Livermore National Laboratory under Contract W-7405-Eng-48. 


\title{
Dynamic Data-Driven Event Reconstruction for Atmospheric Releases
}

\author{
Gayle Sugiyama, Branko Kosovic, William Hanley, Gardar Johannesson, \\ Shawn Larsen, Gwen Loosmore, Julie Lundquist, Arthur Mirin, John Nitao, \\ Radu Serban, and Kathy Dyer
}

\begin{abstract}
Project Description
For atmospheric releases, event reconstruction answers the critical questions - How much material was released? When? Where? and What are the potential consequences? Inaccurate estimation of the source term can lead to gross errors, time delays during a crisis, and even fatalities. We are developing a capability that seamlessly integrates observational data streams with predictive models in order to provide the best possible estimates of unknown source term parameters, as well as optimal and timely situation analyses consistent with both models and data. Our approach utilizes Bayesian inference and stochastic sampling methods (Markov Chain and Sequential Monte Carlo) to reformulate the inverse problem into a solution based on efficient sampling of an ensemble of predictive simulations, guided by statistical comparisons with data.
\end{abstract}

\section{Expected Results}

We are developing a flexible and adaptable data-driven event-reconstruction capability for atmospheric releases that provides (1) quantitative probabilistic estimates of the principal sourceterm parameters (e.g., the time-varying release rate and location); (2) predictions of increasing fidelity as an event progresses and additional data become available; and (3) analysis tools for sensor network design and uncertainty studies. Our computational framework incorporates multiple stochastic algorithms, operates with a range and variety of atmospheric models, and runs on multiple computer platforms, from workstations to large-scale computing resources. Our final goal is a multi-resolution capability for both real-time operational response and high fidelity multi-scale applications.

\section{Mission Relevance}

This project directly contributes to the laboratory's homeland and national security mission by addressing a critical need for atmospheric release event reconstruction tools to support the rapidly growing number of operational detection, warning, and incident characterization systems being developed and deployed by the Department of Homeland Security (e.g., BioWatch, BWIC system, national BioSurveillance Initiative) and Department of Energy (e.g., Nuclear Incident Response Team assets and deployments). The event reconstruction and sensor siting tools developed by this LDRD are targeted for integration into the next-generation National Atmospheric Release Advisory Center and DHS's new Inter-agency Modeling and Atmospheric Analysis Center, based at LLNL.

\section{Accomplishments and Results}

In FY04, we: (1) implemented a 2D prototype Bayesian MCMC atmospheric event reconstruction capability and tested it against a variety of scenarios and synthetic data; (2) developed a MCMC capability using the NARAC 3D Lagrangian particle dispersion code LODI and tested it against field experiment data; (3) developed a SMC methodology for time-dependent problems and tested it using synthetic data; (4) investigated optimization methods for determining proposal distributions and improving convergence; (5) evaluated the relative performance of MCMC and SMC methods using synthetic data; (6) designed a MCMC and SMC computational framework 
on massively parallel platforms; and (7) demonstrated the effectiveness of the SMC methodology for detecting moving sources using synthetic data.

\section{Proposed work for FY05}

In FY05 we will: (1) implement a SMC atmospheric event reconstruction capability based on NARAC operational models; (2) develop procedures and tools for input and model error quantification necessary for the event reconstruction framework; (3) extend the event reconstruction capability to handle complex terrain and an extended range of potential release types; (4) develop a multi-resolution capability for problems requiring multiple levels of models to accurately characterize the release event; (5) continue developing and testing efficient stochastic sampling and convergence algorithms; (6) explore methods for incorporating alternative input data types (e.g., remote sensing, qualitative, imagery); and (7) enhance performance on massively parallel platforms for efficient event reconstruction of complex atmospheric releases.

\section{Publications}

Kosovic, B., 2004: Dynamic Data-Driven Event Reconstruction for Atmospheric Releases, Energy and Environment Directorate Review Committee, April 8, UCRL-PRES-203246.

Kosovic, B., G. Sugiyama, K. Dyer, W. Hanley, G. Johannesson, S. Larsen, G. Loosmore, J.K. Lundquist, A. Mirin, J. Nitao, R. Serban, 2004: Dynamic Data-Driven Event Reconstruction for Atmospheric Releases, Second Sandia Workshop on Large-scale PDE-Constrained Optimization, Santa Fe, NM, May 19-21, UCRL-POST-204204.

Sugiyama, G., W. Hanley, B. Kosovic, J. Nitao, S. Larsen, G. Johannesson, G. Loosmore, J. Lundquist, A. Mirin, R. Serban, and K. Dyer, 2004: Dynamic Data-Driven Event Reconstruction for Atmospheric Releases, University of California, Science and Technology Panel, UCRL-PRES-204651

Kosovic, B., G. Sugiyama, K. Dyer, W. Hanley, G. Johannesson, S. Larsen, G. Loosmore, J.K. Lundquist, A. Mirin, J. Nitao, R. Serban, 2004: Dynamic Data-Driven Event Reconstruction for Atmospheric Releases, $8^{\text {th }}$ Annual George Mason University Transport and Dispersion Modeling Conference, Fairfax, VA, July 13-15, UCRL-PRES-205169.

Sugiyama, G., K. Dyer, W. Hanley, G. Johannesson, B. Kosovic, S. Larsen, G. Loosmore, J.K. Lundquist, A. Mirin, J. Nitao, R. Serban, 2004: Markov-Chain Monte-Carlo and Sequential Monte-Carlo Approaches to Dynamic Data-Driven Event Reconstruction for Atmospheric Releases, Second Workshop on Monte Carlo Methods, Boston, MA, August 27-28, UCRL-POST-206484

Johannesson, G., W. Hanley, and J. Nitao, 2004: Dynamic Bayesian Models via Monte Carlo: An Introduction with Examples, UCRL-TR-207173.

Nitao, J., 2004: The use of Reciprocity in Atmospheric Source Inversion Problems, UCRL-TR-207262 